OPEN ACCESS

Edited by:

Claude-Hélène Mayer, University of Johannesburg,

South Africa

Reviewed by:

Nikolett Eisenbeck,

Seville University, Spain

David F. Carreno

University of Almería, Spain

*Correspondence:

Heesoon $\mathrm{Ba}$

hbai@sfu.ca

†These authors share first authorship

Specialty section:

This article was submitted to Educational Psychology,

a section of the journal

Frontiers in Education

Received: 30 December 2020 Accepted: 02 March 2021

Published: 23 March 2021

Citation:

Bai H, Berry K, Haber J and Cohen A (2021) Dancing With Non-duality for Healing Through the Shadows of the COVID-19 Pandemic. Front. Educ. 6:647764. doi: 10.3389/feduc.2021.647764

\section{Dancing With Non-duality for Healing Through the Shadows of the COVID-19 Pandemic}

\author{
Heesoon Bai ${ }^{1 \star t}$, Kevin Berry ${ }^{1 t}$, Jesse Haber ${ }^{2 t}$ and Avraham Cohen ${ }^{3 t}$ \\ ${ }^{1}$ Faculty of Education, Simon Fraser University, Burnaby, BC, Canada, ${ }^{2}$ School of University Studies and Career Access, \\ College of New Caledonia, Quesnel, BC, Canada, ${ }^{3}$ Adler University, Counsellor Education, Vancouver, BC, Canada
}

The COVID-19 pandemic has unleashed torrents of global suffering at a devastating scale, necessitating a strong response to alleviating suffering. This paper begins with noting that the conventional approach to suffering in North America is to be positive and not to be negative. The paper summarily explores the philosophy of positive psychology underlying the first- and the second-wave of positive psychology, commenting on the evolution from dualism and a binary conceptualization in the first wave (PP 1.0) to a non-dualism of integrating binaries in the second wave (PP 2.0). PP 2.0's enhanced therapeutic efficacy is noted for its non-dual framework. The paper then explores and suggests a different conceptualization possibility of non-duality, fundamental non-duality, that is related to but distinct from the one in PP 2.0. A case is made that fundamental non-duality has a radical possibility of therapeutic efficacy. Being consistent with the philosophy of non-duality, further suggestions are made that non-duality of PP 2.0 and fundamental non-duality can be therapeutically deployed together for greatest efficacy. The exploration contained in the paper is largely philosophical, arts-based, and autobiographical, creating an enacted and lived experience of applying theory to practice.

Keywords: COVID-19, non-duality, positive psychology, shadow work, psychotherapy, AEDP, wisdom traditions, dialogue

True seeing is called transcendence;

False seeing is worldliness:

Set aside both right and wrong,

And the nature of enlightenment is clear.

Hui-Nang (Cleary, 1998)

\section{OVERVIEW OF THE FIRST- AND THE SECOND-WAVE OF POSITIVE PSYCHOLOGY}

The COVID-19 pandemic has turned the world upside down and inside out, unleashing torrents of global suffering. The staggering figure of 2.42 million marks the total worldwide number of deaths from COVID-19 as of February 16, 2020. While the newly released vaccination is promising, and hope rises that the pandemic will finally be over by fall 2021, the scale of devastation and suffering is such that there will surely be no "back to normal" in any foreseeable future: if ever at all. How do humans cope with such degree of rapid change, duration of ordeal, and all the associated feelings, particularly fear and anxiety stemming from uncertainty, and grimness? What do we know about 
human resilience in the face of prolonged and major challenges and ensuing suffering? After all, humanity has faced these pandemic situations many times, since time immemorial.

When we are confronted with suffering, most of us, at least in our modern North American cultural context, have been "trained" to look on the bright side, find and focus on the positive, and disavow the negative. The professions of modern psychology and psychotherapy have been part of this training in that its main mission is to identify and resolve or replace what have been deemed "negative" emotions (Horwitz and Wakefield, 2007). Dependent upon which modality a practitioner works from, this could mean that these negative emotions are, for example, replaced with positive emotions, alternative perceptions, or survival strategies of one type or another-typically with the aim of negating the negative over all else. This negativity bias has led to a profession of psychotherapy and a mental health lexicon that approaches healing primarily from a pathologizing, symptomcenterd frame of reference (Gaj and Castiglioni, 2020), meaning that these professions tend to privilege negative emotions over positive emotions. In response to this pathologizing frame, the 2000s saw the birth of first-wave positive psychology as a step toward acknowledging the important role of positive emotions in healing (Fitzpatrick and Stalikas, 2008).

Positive Psychology as an area of study has seen much attention since its entrance onto the world stage with Martin Seligman's President address at the American Psychological Association Annual Report in 1998 (Seligman, 1998). This iteration of positive psychology was largely ambivalent toward negative emotions, believing as though focusing on the positive would undoubtedly eradicate the negative. However, this view received criticism for just that-failing to attend to negative emotions, in which individuals incorporate an over-emphasis of positive within their appraisals of situations (Miller, 2008). Focusing predominantly on "positive emotion, positive character, and positive institutions" (Seligman et al., 2005, p. 410) has been characterized as being lopsided, neglecting the negative or shadow side of the human experience (Miller, 2008; Bai and Cohen, 2019). In particular, criticism has been leveled at the notions that (1) life is about achieving goals; (2) that our emotions, traits, and dispositions may be conscious and subject to conscious change; and (3) that well-being is grounded in spending time immersed and absorbed in specific strength-based activities (Miller, 2008, p. 593). An additional fallout of this approach is that (4) it very frequently leads to a new problem, namely, high levels of self-criticism and doubt related to one's inability to perform this operation (Yakushko and Blodgett, 2018). As well, (5) the terminology of positive and negative fails to acknowledge the adaptive and the growth potential of all emotions (Meichenbaum, 2012).

From these and other criticisms, Wong (2011) and others (Lomas, 2016) endeavored to move Positive Psychology (PP, henceforth) from its first version (PP 1.0) to a more integrated version. Wong (2011) coined "PP 2.0" to call this second version: the second-wave of Positive Psychology. Second-wave positive psychology, PP 2.0, re-examined the ambivalent stance toward negative emotions and acknowledged suffering as foundational in human existence, seeking to transform suffering into wellbeing and strengths (Wong, 2011). PP 2.0 aims to incorporate not just the neutral and positive experiences and emotional landscapes of life as outlined by Seligman and Csikszentmihalyi (2000), but also the negative territories in day-to-day living (Wong, 2019). Essentially, PP 2.0 conceptualizes life as one in which meaning lies at the forefront of flourishing human experience. By integrating aspects of existentialist thought and positive psychology, Wong (2019) asserts that we need dualism in order to achieve non-duality. We will return to this key point with an alternative or additional interpretation of non-duality. For now, let us continue with our overview of PP 2.0.

What makes PP 2.0 stand out from its predecessor is the focus on a dialectic, balanced view of both the positive and negative aspects of life. Most notably, Wong (2011) asserts that happiness and meaning operate as two distinct and different conceptions of what "the good life" could entail. In integrating a more meaningfocused conceptualization of human flourishing, Wong advocates for a more dialectical yin-yang understanding of the positive and negative, with the objective of finding the balance to be the main aim of therapeutic interventions (Wong, 2021). Here, balance is itself seen as the meaning of wellbeing. Notable in this understanding of wellbeing is, then, that one needs both the negative and the positive emotions and experiences: for, both are necessary ingredients for achieving wellbeing. Wong calls such achievement, "self-transcendence." In this model of wellbeing, transcendence is the creative force that holds opposites together. Suffering and all its emotional manifestations of negativity are not negated or avoided but embraced and transformed. Again, we note that Wong wishes to maintain the dual-system of the positive and the negative, with an intent to navigating between the two and arriving at an integrative or balance point.

Over the past 10 years, PP 2.0 has received increasing support through research and publications of scholarly articles (Wong, 2021). However, it has remained centered on asking the question: how do we flourish through suffering? From this question, other clinicians have also begun to use PP 2.0 as a means to working with and for clients who are trying to make sense of troubling times (Van Tongeren and Showalter Van Tongeren, 2020), all with the aim of finding the overlapping area of our most profound existential concerns, such as death, isolation, groundlessness, and the interests of Positive Psychology, such as virtues, relationships, and religion. In this nexus, practitioners of PP 2.0, recently re-named "existential positive psychology" (Wong, 2021), hope to find the means to not only flourishing through suffering, but also to embracing what Victor Frankl (2006) calls "the will to meaning."

The authors of the present paper find Wong's PP 2.0 to be both realistic and robust. We cannot keep the negative out of our daily life, even if we expend a lot of energy and effort, which is ultimately counterproductive. In fact, if the negative can be harnessed to yield transformation, such a model is far more robust than one that negates the negative and does not make use of its hidden power. We suggest, however, that PP 2.0, in seeking to transform the negative into the positive, is in effect still at least half-way committed, philosophically and theoretically, to the duality and the binary of the positive and the negative human experience. Wong (2021) has stated clearly that we "need the 
dual-system approach to achieve non-duality that good and evil are two sides of the same coin" (Wong, 2021, para. 15).

If good and evil are two sides of the same coin, then the coin must represent transcendence. In the next section we will explore the meaning of transcendence in terms of the conceptualization of non-duality as it pertains to negative and positive experience. Our exploration will take an interdisciplinary turn, involving neuropsychobiology and philosophy, with an eye toward drawing out therapeutic implications from the wisdom of non-dual philosophy and practice.

\section{ROOTING FOR THE WISDOM OF NON-DUALITY}

The tendency of human beings to see the world in separatedout units and entities, and also in binaries of what is good/bad, what is right/wrong, what is useful/useless, and so on, is deep seated. Our observation finds support for the above reasoning and understanding in contemporary neurobiological research. As survival-oriented animals, humans have the capacity to make split-second decisions to run (or fight or freeze) for their life when faced with mortal threats. Such "decisions" do not require reflection and deliberative cogitation: the capacity to check the veracity of the situation, weigh evidence, consider different possibilities of response and their ethical and practical merits, and imagine long-term consequences. As such, these rapid-response decisions are made involuntarily in the lower regions of the brain before the conscious and deliberative thinking parts of the brain (prefrontal cortex) have any chance to get involved (Ginot, 2017). For, the slow process of conscious deliberation is liable to place the person facing a mortal threat into a position of mortal danger, such as, right into the chasing tiger's mouth. In such a situation, it is best, survivalistically speaking, to be in the mode of, "Don't think; just run-fast!" Following this train of thought, we would say that dualism and accompanying binary thinking are closely associated with a survivalistic mode of being. For example, in a threatening environment, we would ask: "Are you, or are you not, my enemy?" Under survivalism, the other is either one's friend or one's foe. One has to decide and act at lightning speed.

Dualism and its binary ways of seeing have their place in human survival. However, such unconscious and automatic ways of perceiving and acting may well get us into trouble in our increasingly complex and complicated relational lives that define today's sociopolitical, cultural, and ecological contexts. For, the latter requires us not to make split-second binary, reactive moves of running away or attacking and fighting, but instead to move into continuum-based and creatively interpretive, multiple ways of perceiving and thinking to optimally protect and support all beings, including human beings. The propensity to take a binary view as an endpoint is majorly limiting to human adaptability in terms of deployment of resources and creative problem-solving.

As well, problematic ethical implications could follow from dualism and its binary thinking. Consider a literary example, a short sermon from the character of Father Paneloux in Albert Camus' (1971) The Plague. Following the onset of the mysterious plague in the city of Oran, Father Paneloux delivers a fiery sermon on how the town's inhabitants brought these circumstances down on themselves: "For plague is the flail of God and the world His threshing-floor, and implacably He will thresh out His harvest until the wheat is separated from the chaff" [added emphasis] (1971, pp. 80-81). In this description, the Father is treating the wheat as separate from the chaff, as though, without the chaff the wheat could have grown and flourished on its own.

By delineating between the positive (desirable) and negative (undesirable) parts of the harvest, the Father is unable to see how one is of the other-that one requires the other in order to be. How does the wheat get to the threshing-floor without the chaff to hold it, protect it, grow with it? We contend the crucial element of contingency is missing in Father Paneloux's sermon: without the chaff, there is no wheat and vice versa. Human existence is both the wheat and chaff, and all efforts to treat them as non-contingent obfuscates their innate wholeness. Also, consider the implications of this thinking when it comes to the victims of both Father Paneloux's plague as well as our own: if we are disregarding the chaff as undesirable, are we, too, disregarding the victims of COVID-19 as somehow deserving of their fate? We contend that endorsing this kind of morality has dire and horrendous consequences, namely, that as a society we have begun the process of devaluing human life contingent only on who the plague strikes down-as those who deserve to be left on the threshing-room floor.

Now turning to the geographical East in origin, Thich Nhat Hanh, the Vietnamese Zen Monk, says simply, "no mud, no lotus" (2014). This image and idea run in contrast to Father Paneloux: namely, that without the mud, the lotus flower is unable to grow and flourish. When one is on a walk and stops at the foot of a muddy pond, does one usually look down and say "here is the grounds for great flourishing!" Or, is one more likely to simply look in disgust at the murky gray-brown dirty pool, and try their best to avoid it? Again, we who have been conditioned into binary thinking would see the dichotomy of undesirable and desirable; mud and lotus. It is our binary thinking habit that sees the mud as undesirable (negative) and the lotus most desirable (positive). The eye of wisdom would not see that mud and lotus as opposites. Mud and lotus are continuous on the plane of being. There are, to begin with, no duality and binary here. Thich Nhat Hanh asserts, without the mud, no beautiful lotus could emerge: they are, for all intents and purposes, parts of the same whole. This, to us, is a more fundamental meaning of non-duality: seeing continuity and hence wholeness prior to dualistic distinction and naming. Integrating and balancing the binaries, as in PP 2.0, that already showed up and became entrenched in human consciousness is an interventionistic measure of non-duality, not a fundamental measure. Again, we are not implying or suggesting that we should choose between the two measures for the meaning of non-duality. We can have both just like having both preventive medicine and emergency medicine.

It is illuminating to reflect on the history of humanity and ask whence comes the injunction not to react out of automatic pattern recognition (Is it a tiger or isn't it a tiger?) and action (Run, fight, or faint?) but to respond after perspectival and deliberative thinking (Perhaps, seen from this angle, it's not a tiger?) and interpretive and imaginative considerations (What 
if I invited the tiger to share my take-out dinner?). According to the theory of the so-called Axial Age (Armstrong, 2007), promulgation of such thinking seems to have been part of the rise of wisdom traditions that began all over the world, more or less simultaneously, during what is known as the Axial Age, a period between the eighth century and the third century BCE. The messages, and injunctions, of love and compassion, not just for one's tribes and kinfolks but for all humanity and beyond (all sentient beings, even all existential beings), have been making their way through human history ever since.

It is further illuminating to note as well, without elaborating in the present paper, that such teachings of pan-humanism and pananimism are still, if not more than ever, supremely challenging to human beings, even today, 2,500 years since the inception of the Axial Age. To be clear, the previous statement is not meant as a searing criticism of humanity but rather recognition that much still needs to be done at all levels of education, including the family, to develop a generative consciousness that has these capacities and abilities, or at least in the process of developing them. We consider our proposed fundamental non-duality to be part of this generative consciousness.

The deep-rooted cognitive habit, such as the dualistic and binary thinking of seeing everything in the categorical terms of negative/positive, good/bad, pain/pleasure, winning/losing, success/failure, us/them, me/others (this list can go on), puts a major limitation on human capacity for responsibility-taking and caring for all and whole, which is being witnessed in so many sociopolitical, cultural, and environmental situations of conflict, denial, and complicity around the world today. Even in PP 2.0's non-duality that starts with the binary seeing and thinking so as to move toward integration and balance, this starting point of binary thinking already limits our possibilities of response to constantly emergent human situations.

Theoretically speaking, the limitation of binary thinking lies foremost in its not fully embracing reality that, by all accounts, is fundamentally about unimaginably complex, dynamic multiplicity, and interconnection: the world, the universe, the reality is, to begin with, an interconnected whole in constant change and flow (Macy, 1991). While distinctions of parts, degrees, and irreducible uniqueness may remain amongst the existents, any time our habit of mind activates binary thinking, we tend to, almost invariably, lose sight of the interconnected whole and descend into prioritizing one over the other, pitting one against the other, and we often try to eliminate one side: the side we deem to be the negative or the undesirable. Except when situations are so dire as to require us to resort to the automatic binary perception and decision-making, as, for example, when a tiger leaps out and pounces us, by and large, a more flourishing life of wellbeing and goodwill would be better had by all of us, if we operate out of non-dual and non-binary ways of experiencing the world. In this regard, we agree that PP 2.0's approach that focuses on balance and harmony, in working with existing binaries, does much to bring about happiness and wellbeing (Wong and Bowers, 2018). With our offering of the conception of fundamental non-duality, we share the same goal.

The fundamental non-duality perspective has us see and validate the dynamic, processual interrelatedness of the all sides that may at first glance be considered separate, unrelated, and even, oppositional. It is the second glance that is crucial here: seeing again ("re-spect," again-seeing) in order to discern the interrelatedness of the parts that make up a whole. Thus, fundamental non-duality comes out of a philosophy of holism. Holism teaches us how to look in ways to see through the eyes of generosity, compassion, and transcendental understanding what seems at first sight conflicting and, even, "horrifying" and "disgusting." Wong's work on PP 2.0 is, we believe, inclining us in this direction of holism and transcendence. We believe what we are adding here is an articulation of fundamental non-duality that is logically and spiritually prior to the PP 2.0's non-duality. Many of world wisdom traditions, for examples, Buddhist and Daoist philosophies that the authors of this paper are familiar with, expound and teach this kind of fundamental non-duality.

\section{THE VARIETIES OF NON-DUALITY}

Alongside PP 2.0, the authors of this paper advocate a non-dual philosophy, perspective, and healing approach to encountering and working with human suffering, such that the current COVID-19 pandemic has unfurled at a massive scale. It is our hope that our conceptual explication of the fundamental meaning of non-duality further enriches and substantiates $\mathrm{PP}$ 2.0. In the present section, what we propose to do is illustrating, using a few examples of the pre-existing work, how we may apply fundamental non-duality to working with suffering that typically involves negative and positive (and neutral) emotions and experiences. What we are advocating is, first of all, seeing beyond the negative and the positive (and neutral). This seeing involves moving into a zone of fundamental non-dual consciousness, which can be characterized as an under-determinate non-discursive space of potentiality, such as mindfulness meditative state, that may be experienced prior to particularistic conceptualization of the negative and the positive.

With the above understanding, we invite our readers to consider three examples of working with non-duality, including a conception of fundamental non-duality. However, in giving a brief mention of these examples below, our interest is not recommending that they become part of PP 2.0 (or the other way around, either). Rather, these examples serve the illustrative purpose of our main thesis: namely, that there are various ways to conceptualize and work with non-duality concerning our being and becoming, and, moreover, all these different ways may show solidarity with each other in helping us to face life's inevitable challenges. The first example below, AEDP seems to lie closer to PP 2.0's non-duality than the conception of fundamental non-duality that this paper proposes. The other two examples following the first one move further toward fundamental non-duality.

There are other examples of therapeutic modalities that work with conceptions of non-duality, such as the Acceptance and Commitment Therapy and others that are based in or informed by mindfulness practice. Due to space limitations, we will not include these in the present paper; however, we find it hopeful and exciting that binarism is increasingly seen as limiting our 
healing possibilities and that mindfulness and other wisdom inspired practices are being integrated into therapy to go beyond these limitations. We the authors of this paper suggest that fundamental non-duality gives us an additional room in our healing capacity.

\section{Example One: Accelerated Experiential-Dynamic Psychotherapy (AEDP)}

Concurrent with PP 1.0, Diana Fosha developed a psychotherapeutic modality called Accelerated ExperientialDynamic Psychotherapy (henceforth, AEDP) (Fosha, 2000). However, whereas PP 1.0 privileges the positive aspects of humanity within its healing process, AEDP takes a more integrated approach, akin to PP 2.0, to healing by bridging the traditional therapeutic stance of ameliorating symptoms and psychopathology and positive psychology's focus on positive affect and psychological flourishing (Fosha and Thoma, 2020). Consequently, as an integrated, healing-oriented, experiential therapy based on attachment theory and affective neuroscience, AEDP is positioned as an effective transdiagnostic integrative therapy to address a wide range of symptoms including depression, anxiety, hopelessness, relational trauma, and social isolation that are exacerbated by the COVID-19 pandemic, which has accelerated mental health practice into crisis work (McBride et al., 2020).

AEDP acknowledges that (1) defense mechanisms are both adaptive at one point in time, and maladaptive in another; and (2) that engaging with maladaptive sequelae and suffering can in turn facilitate an adaptive change process that facilitates transformational healing. Within this process, AEDP illustrates for us several key elements that are effective in healing of pain and suffering that can be considered within a nondualist framework. Through a four-state phenomenological process, AEDP alchemizes energy-depleting negative emotions into energy-enriching positive emotions to turn suffering into flourishing (Fosha, 2019a). The aspect of AEDP that inclines itself toward fundamental non-duality is its intimation of the Daoist way of working "alchemically" with energetics (Mitchell, 1988). Experientially speaking, energetics (vital energy or lifegiving force, known as chi in Chinese, $k i$ in Korean and Japanese, or prana in Sanskrit) emerge prior to the conceptualizations of negatives and positives.

There are four states to AEDP. During State 1, the therapist co-creates relational safety by engaging in dyadic affect regulation of client-therapist relatedness-that is, calling attention to the strength of the therapeutic relationship and to the fact that what is occurring is a shared experience between the client and the therapist. And also, in alignment with second-wave positive psychology, the therapist intentionally affirms the protective role of the defense mechanisms in the client's life. Through this process, the client feels energetically safe to access painful emotional experiences that cause suffering. In State 2, by connecting deeply with the somatic experience of suffering, clients "[feel] more in touch, more embodied, more real" (Fosha, 2019a, p. 109).
Where other therapies consider successful processing of suffering an endpoint in therapy, AEDP considers it a starting point for further processing. In State 3 metaprocessing (the processing and savoring of having experienced healing), the therapist facilitates the experience of healing, helps the client realize that they have experienced healing, and explores the client's experience of this knowingness; within a relational context, this savoring of the healing experience reinforces adaptive change at an affective level and supports the client's self-efficacy and their capacity to trust another. In State 4 , this experience of knowingness-called the "core state"engenders within the client a state of calm, wholeness, and centeredness-the same qualities of mind that characterize nondualist contemplative practices (Fosha et al., 2019b).

\section{Example Two: "Feeding Your Demons"}

Schooled and trained in a Tibetan tradition of Buddhism, Tsultrim Allione is a Buddhist teacher who developed a program that leads practitioners through five steps of: finding the demon; personifying the demon; becoming the demon; feeding the demon; and rest in awareness. "Demons" are psychological complexes that are formed as a result of having parts of our experience invalidated, divorced, and repressing, in order for us to conform to the demands of familial and societal norms-whatever they happen to be. Allione (2008) states:

\footnotetext{
Demons are ultimate part of the mind and, as such, have no independent existence. Nonetheless, we engage with them as though they were real, and we believe in their existence-ask anyone who has fought post-traumatic stress, or addiction, or anxiety. Demons show up in our lives whether we provoke them or not, whether we want them or not. The mind perceives demons as real, so we get caught up in battling with them. In the end, all demons are rooted in our tendency to create polarization. (p. 44) (italics added for emphasis).
}

This ancient language of "demon," indigenous to the Tibetan Buddhist and Bong traditions, can easily be translated into the contemporary psychological language of reified perception, projection, trauma, addiction, attachment, and the like. And the last point about polarization speaks to the cognitive habit of binary ways and dualism that we have been talking about all along.

"Feeding your demons" is a good example of taking what people experience as concrete, such as reality or beings that are negative, and helping them to go beyond the reified entities (in this case, "demons") by dissolving them into different energy states and returning the practitioners to their own fundamentally non-dual consciousness that is, in the language of Buddhism, pure awareness. Thus, the work involved is not about transforming the negative into the positive, or even about harmonizing or balancing the negative with the positive, as in the case of PP 2.0. Once one sees through the nature of "demons," "feed" them what they have been starved of, fulfilling them, their power subsides. At this point, one is freed from its hooks and shackles (of binary and dualistic ways of thinking and seeing). 


\section{Example Three: Shadow Work}

THERE are many contemporary psychotherapists and psychologists who do "Shadow work," inspired by Carl Gustav Jung. Jung has stated: "We must be aware of thinking of good and evil as absolute opposites. The criterion of ethical action can no longer consist in the simple view that good has the force of a categorical imperative, while so-called evil can resolutely be shunned" (Jung in Zweig and Abrams, 1991, p. 171). Connie Zweig and Steve Wolf give this succinct account of the work (Zweig and Wolf, 1997):

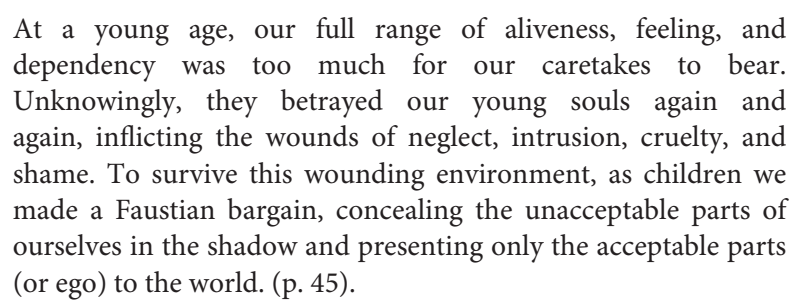

The first thing to note in the above description is that the negative (i.e., the shadow parts) does not have an independent and substantive existence, as with the "demons" in the above second example. It is constructed: in this case, it is made of invalidated experiences of ourselves, as a result of being subjected to socializing and normalizing forces. As well, Zweig's explication points to an important point, namely that the invalidated, therefore, concealed parts hold the energy of aliveness that was denied of a young developing person, which further explains how working with the content of the shadow-what is underneath the ego configuration-would release life energy, which is enlivening and life-enhancing.

As with the work of "Feeding your Demons," Zweig's version of shadow work (1997) also has some practical advice, tips, and instructions (pp. 310-316). Especially valuable are grounding and centering practices that "quiet your mind, settle your emotions, relax your body": for, shadow work is emotionally challenging, even threatening to undo our ego formation and structure. The locks that are put on these "dark" materials are, precisely, negative emotions that are designed to scare and pain us: fear, anxiety, depression, despair, hopelessness, and so on.

Darkness disappears, not by removing darkness, but by illumination. Darkness is not substantive. It has no independent existence. As soon as we turn on the light, darkness disappears. So much of our therapeutic work is about removing darkness. But we can take a different approach: let there be light! Like the practice of "feeding the demon," we can feed darkness with light. When a soul (the most sensitive part of a self) is nourished and becomes fulfilled or fully filled, shadows may likely disappear on their own, for, they have no substantive existence of their own.

\section{EVERY MOMENT IS PREGNANT WITH HEALING POTENTIAL-A DIALOGUE}

The motivation and impetus behind writing this paper is to find deep and expansive ways of responding to, and hopefully healing from, the COVID-19 pandemic that has been unleashing massive suffering globally. The three examples above show us that healing is not about eliminating, "getting rid of," or "solving" problems and afflictions, and going back to some state of wellbeing prior to becoming hurt and damaged. As part of the continuous stream and cycle of hurts-and-repair, healing is more about the raw pain from the damage becoming less sharp and more bearable than about the wounds and memories of wounds disappearing or being replaced. The trauma of everyday life reveals, as Mark Epstein (2013) tells us, that every moment opens us to possibilities of damage, hurts, and bruises. We would add that, by the same token, the trauma of every life invites us to enter into the trauma and come out "healed," meaning more wholesome and resilient.

Having reviewed, above, the three examples of therapeutic modalities or approaches that honor fundamental non-duality deeply embedded in us, we the authors would like to further extend the theoretical discussion hitherto by engaging in a dialogue (via email exchanges) in which we disclose and share our personal practice and experiment. What realizations and insights have we gathered?

\section{Dialogue (Dia $=$ Through; Legein $=$ Speak $)$ Avraham}

It is as though the spirit of COVID-19 has arrived to deliver a very powerful, and even deadly, message to us humans, and to the earth, about being awake and about the health of the whole biosphere. As you know, Colleagues, there was a huge drop in pollution levels at the initial stages of the pandemic when many countries around the world imposed massive curtailment of their citizens' movement and activities, which resulted in polluting industries and transportation to slow down and even stop, albeit temporarily. Even as humans were being felled, the earth's atmosphere, forests, and oceans were recovering. Gaia began to breathe much more freely, unrestricted, when humans "rested" deeply.

Perhaps COVID-19 is the Zen stick, the keisalzu, the stick that is used by the Zen master in an effort to wake up sleepy Zen meditators-the humans. The stakes for not waking up are very high for humanity now.

Colleagues, I would like to invite you to share with us your own process of inner work since the eruption of the COVID-19 pandemic, particularly during this writing period while engaging deeply with the themes and thesis of our paper. What insights and realizations have emerged for you? I will start. In the service of getting to know the inner and outer darkness into which the COVID-19 has plunged humanity, I have been engaged in a dialogue with COVID-19 in my inner world. I have personified COVID-19 as my dialogue partner and have given it a voice of its own. Below is my dialogue sample. Of course, please do not take it as any kind of practical suggestion for dealing with the virus. Mask-wearing and handwashing are most essential for not catching the virus. My dialogue with COVID-19 is strictly a psychological inner work.

\section{Covid}

I have arrived to be with you. I would like you to know that the sickness that is epidemic is much greater than just the physical. 
By bringing you down to the survival level, I will show you in your inner world of mind-body-heart-spirit, the sickness-withinthe sickness of your soul, as it were. I don't think you will ever be as you were, prior to engaging with me, whether you are sick with the virus or not. I am really here to teach you, but I don't know if even this will be sufficient for you to get my teaching. Actually, I have been delivering my message, my warnings, all the time, most often in gentler voices. That didn't seem to have worked. I am now shouting, with my mighty, forceful, and sickness-and-death dealing voice, for you to hear. You can call me the enemy, the teacher, or whatever else you like. I am here amongst you.

\section{Avi}

Wow, you are scary! You are killing literally millions of people and causing incredible suffering. But our scientists are developing antidotes called vaccines to defeat you. You will die, and we will be back to the normal.

\section{Covid}

I will tell you here and now that you are so very short-sighted! You may win the battle, but you will not, really cannot, win the war-the war against Nature, against the living planet Earth to which you belong. I already exist in very many forms other than this current one. You humans have invented many words: racism, poverty, disease of all kinds, class, power-over, war, tyranny, and so on. Surely, such inventions are products of a limiting, limited, and dualistic consciousness. Most often, you humans behave as if you are not fully conscious.

\section{Avi}

What are you talking about? I am fully conscious. I am aware. I know what I am doing and feeling. Please tell me what it is that you are talking about? Are you saying that I'm not doing my consciousness right?

\section{Covid}

This is not about "right" or "wrong!" This is about seeing deeply into the world and reality and knowing how they operate. This reality, of course, contains you. You are part of reality and world. And reality is all about dynamic and seamless interconnectedness that makes up the whole. But to see all this, you would need to slow down. Stop frantically running around, as if what matters the most is progress and profit, power-over, achievement, success, competition, and so on.

\section{Avi}

For sure, you are giving me a very tough task. The moment I slow down, noticing my being connected to you, all others, and the natural environment, I start to experience all manner of neurochemistry that signals alarm coursing within me. I need to breathe! Yes, breathe deeply!

\section{Jesse}

Thank you, Avraham, for the invitation to dialogue this process. Dialogue, both inner and outer, has been a central facet of life for me since we collectively began to sever in-person connections, limit human-to-human contact, and reconceptualize what it means to live, play and work in a world ravaged by COVID19. Where I live, the numbers have been, until recently, very low. As such, COVID has been more of a talking-point or intellectual exercise about freedoms and responsibility than an actual threat-a thing to fear at a distance and talk about often. In this space, I encountered many who, after a few months of relative isolation, were "over it," as though impatience with what ails us would easily take the place of a viable vaccine.

Through this process, I have watched myself vacillate between compassion and condemnation. From the relative safety of my geography and work-at-home status, I found it easy to wield the cudgel of righteousness when I heard about my friends and acquaintances defying the latest health recommendation, or downplaying the suffering going on in other parts of the world. How could they, I wondered, be so selfish? How does one flaunt these health guidelines in the name of freedom when that freedom may condemn others to infection, injury, or death? In some ways it made isolation easier for me and others: when your neighbor is the "problem," it is easy to not interact with them. And I was able to do this all under the veneer of social responsibility.

It has also been a time to dialogue about what it means to be connected to one another, and to spend more time with oneself. To see how a disruption of routine, work, and play exposes the suffering that lies beneath the day-to-day automation of living. It has shown me and many others what boredom looks like (unless of course, one was working on the frontlines), and how we fill it. It has asked us what we are willing to do for one another and what cost we are willing to pay. For me, it has been a reminder to remember that we all come from our own spaces, contexts, and contingencies. It is a time to have conversations about who takes care of who in our society, and what that means when things get difficult. In a lot of ways, as Avraham mentions, it is a time to see that maybe our footprint on the world can be lessened, if we cared enough to do so.

It is that last line, about "caring enough to do so," that brings up the most suffering for me. It is heart-wrenching to see that we, as a species, can come together to help, heal, regrow, transform, and persevere while at the same time also demonstrating the capability to retreat into isolationism, egoism, and greed (just remember the toilet paper shortages of the early pandemic). It is a dark space to sit in, and my own process has been about finding compassion within that darkness and also to learn that the darkness has something to teach me as well.

Those lessons are what I hope "transformation," as is mentioned above, looks like in my own process. In seeing how I judge and react I find myself needing to constantly question feelings that arise quickly and without warning: What do they tell me about living with my own suffering? What does my reactionary righteousness teach me about my own coping mechanisms and binary thinking? How might I learn to identify this sooner and dissolve the categorical boundaries of right/wrong - to find the nuance and flow of other people's actions, and how might I see their suffering with more clarity and compassion? Finally, can I use the reminder of my reactivity to act as a signal, an internal notifier, to embrace the complexity and intersubjectivity that I so easily espouse when times are good?

\section{Kevin}

Thank you, Jesse, for your insights around connection-both with others and with ourselves. For years, I found myself enthralled by the notion that if I were to just appraise experiences 
with a more positive bias, like, "yes, I suffered, but...," that would lessen my, and others', suffering. It was the arrival of the global COVID-19 pandemic, in which suffering is overtly a collective experience, which shifted my rather exclusionary and binary perspective to a more non-dualist view, as this paper has endeavored to show. The whole world is suffering! At times, there have been glimmers of adaptive functioning. I don't deny that. But the pandemic has taken from us the close physical connections. It has really been the acknowledgment and the respect for the suffering and mourning that has unleashed a new current upon which my lifeforce can now flow.

At the start of the pandemic, like many, I mourned not being able to see friends in person; moreover, it seemed a chill descended upon the invitation to even engage with strangers on open streets; thus, like the rest of the world, I began to transition my social connection online. But without the sources of vitality afforded by physical connection with others and (thanks to a reliance on sitting in front of a computer screen) without a sufficient outlet for the physical body's inclination to move, kinetic energy was building inside. I was becoming anxious and disoriented, and ultimately suffering by experiencing loneliness. Collective suffering of separation brought on by the pandemic was reflected in the overwhelming response by volunteers to meet the increased need of mental health supports such as KidsHelpPhone. The desire to be connected to someone was strong.

By allowing for, and working through, my own suffering and feelings of aloneness, I have developed a deeper understanding and compassion for the nuanced ways I both desire connection and separation from others. As a result, I would say, adaptive behaviors previously unexplored have become available to me. As well, through experiencing suffering and becoming curious about it, I have been able to come to appreciate negative, energyconsuming suffering for the adaptive insights it affords. The latter may not have been revealed through a positive appraisal.

Healing and change came about when I began to look at suffering and flourishing not as separate from one another, but distinctly integrated in a non-dualist framework. Through the painful emotional experiences that cause suffering, flourishing can blossom. "No mud, no lotus," said Thay (Hanh, 2014). Exemplifying this philosophy within its theoretical framework and its therapeutic process, AEDP, for example, requires that clients connect deeply with their somatic experience of suffering in order to bring about the experience of flourishing. From the non-dual perspective, that experience of flourishing is a transmutated product of the suffering itself.

Despite recovering from hip replacement surgeries during the pandemic, it was through accepting and creating space for the experience of loneliness, that allowed me to engage differently-and adaptively-with the world and, ultimately, with myself. I acknowledged my suffering-knowing that it was there to protect me somehow-to signal to me that something needed to change. I began to seek out ways to channel my negative energy-consuming suffering adaptively. With the relational safety of supportive and loving parents, I was able to explore seekingoriented adaptive action tendencies (Fosha, 2013) released by fully experiencing my loneliness-including engaging more deeply with my own inner work, with solitude, with nature, and with my physical self-which led to a rediscovery of my own selfacceptance, affective competence (that I could effectively engage with suffering-i.e., loneliness-and transform it into flourishing), and even physical competence.

\section{Heesoon}

Colleagues, in listening to you, I can well relate to what every one of you have experienced and expressed. Fear, resentment, frustration, loneliness. all sitting side-by-side with empathy, compassion, and, often, disbelief (how can this happen?). Yet, again and again, I return, like a homecoming pigeon, to the essential teachings of the historical Buddha, especially, the first "Lecture" he gave after he became enlightened: The Four Noble Truths. I knew about them and even agreed with them for all these decades that I have been a student of the Buddha's teachings. No, I am not a Buddhist! I don't subscribe to ideological or dogma-based allegiance. I am a student of Buddha's teachings, just as I am a student of so many other world wisdom traditions and philosophies. But it is now, during the pandemic, when, as Kevin put it, "all is suffering," that I came to most deeply appreciate the teaching. The Four Noble Truths basically spells out the NO EXIT sign about life and suffering. Suffering is our existential condition, built into what it is to be human. Such being the case, deliverance from suffering, however, does not come from eliminating suffering. Rather, it comes from completely immersing the self in it, becoming one-with-it, and seeing its nature as fundamentally non-dual.

After the initial panic, I settled down and have been "sitting still" (in my consciousness), wrapped up in COVID-19 "in/security blanket," studying "my" (in actuality, "all”) suffering. Waves of suffering comes and goes. In those moments of stillness between ebb and flow, when the anxiety vibes subside and hair-raising fear gives away to the recognition of "NO EXIT, ONLY ACCEPT," there descends extraordinary calmness: a transcendental experience of "beyond" dualism and binaries, of life and death, pain and pleasure, positive and negative, gain and loss, us and them. This is, as I know to be, the essence of Zen. My mind is not divided into two, between suffering and not-suffering, pain and pleasure, my wants and my don't-wants, the positive and the negative. Just suchness. Moments of experiencing wholeness.

\section{CODA}

In this paper, the authors have supported the development of PP 2.0, acknowledging that embracing both the positive and the negative of life experiences gives us more resources and space in working with our afflictions. At a time when the scale of suffering is very great, such as now with the COVID-19 pandemic that has been affecting the global humanity for over a year, we certainly need an expansive way of understanding life and working with our suffering. Invoking Eastern wisdom traditions of non-duality, the authors of this paper have made a case that we can extend the PP 2.0's conceptualization of non-duality. We have shown that there is a conception of non-duality that is prior to working with 
given binaries: fundamental non-duality. All binaries are human conceptualizations that, all-too-easily, slip into reifications and objectifications. Such is a reminder for us to progressively learn to see through the wisdom eyes of fundamental non-duality, which can reveal to us new and numerous possibilities of understanding and responding to global-scale challenges. The final words go to Jesse Haber's Haiku:

Icicle dripped dawn shadows dance, falling in time non-duality

\section{REFERENCES}

Allione, T. (2008). Feeding Your Demons: Ancient Wisdom for Resolving Inner Conflict. New York, NY: Little, Brown and Company.

Armstrong, K. (2007). The Great Transformation: The Beginning of Our Religious Tradition. New York, NY: Anchor Books.

Bai, H., and Cohen, A. (2019). "Ma of education", in Ma: Materiality in Teaching and Learning, eds P. Sameshima, B. White, and A. Sinner (New York, NY: Peter Lang Publishing), 17-32.

Camus, A. (1971). The plague. Great Britain: Penguin Books.

Cleary, T. (1998). The Sutra of Hui-neng, Grand Master of Zen. Boston: Shambhala Publications.

Epstein, M. (2013). The Trauma of Everyday Life. New York, NY: Penguin Books.

Fitzpatrick, M. R., and Stalikas, A. (2008). Positive emotions as generators of therapeutic change. J. Psychother. Integr. 18, 137-154. doi: 10.1037/1053-0479. 18.2.137

Fosha, D. (2000). The Transforming Power of Affect: A Model for Accelerated Change. New York, NY: Basic Books.

Fosha, D. (2013). AEDP: Healing-Oriented, Transformation-Based. PDF File. https://aedpinstitute.org/wp-content/uploads/2013/04/Diana-FoshaPresentation-p27-51.pdf (accessed December 26, 2020).

Fosha, D. (2019a). In the light: on meta-experience and spiraling effects in psychotherapy-commentary on Louis Sass's commentary on Diana Fosha's commentary on Nicole Vigoda Gonzalez's case of "Rosa". Pragmat. Case Stud. Psychother. 15, 105-115. doi: 10.14713/pcsp.v15i1.2049

Fosha, D., and Thoma, N. (2020). Metatherapeutic processing supports the emergence of flourishing in psychotherapy. Psychotherapy (Chic). 57, 323-339. doi: $10.1037 /$ pst0000289

Fosha, D., Thoma, N., and Yeung, D. (2019b). Transforming emotional suffering into flourishing: metatherapeutic processing of positive affect as a transtheoretical vehicle for change. Couns. Psychol. Q. 32, 563-593. doi: 10.1080/ 09515070.2019.1642852

Frankl, V. (2006). Man's Search for Meaning. Boston: Beacon Press.

Gaj, N., and Castiglioni, M. (2020). Fostering the reconstruction of meaning among the general population during the COVID-19 pandemic. Front. Psychol. 11:567419. doi: 10.3389/fpsyg.2020.567419

Ginot, E. (2017). The enacted unconscious: a neuropsychological model of unconscious processes. Ann. N. Y. Acad. Sci. 1406, 71-76. doi: 10.1111/nyas. 13404

Hanh, T. N. (2014). No Mud, no Lotus: The art of Transforming Suffering. Berkeley, CA: Parallax Press.

Horwitz, A. V., and Wakefield, J. C. (2007). The Loss of Sadness. Oxford: Oxford University Press.

Lomas, T. (2016). Flourishing as a dialectical balance: emerging insights from second-wave positive psychology. Palgrave Commun. 2:16018. doi: 10.1057/ palcomms.2016.18

Macy, J. (1991). Mutual Causality in Buddhism and General Systems Theory: The Dharma of Natural Systems. Albany, NY: State University of New York Press.

McBride, H. L., Joseph, A. J., Schmitt, P. G., and Holtz, B. M. (2020). Clinical recommendations for psychotherapists working during the Coronavirus (COVID-19) pandemic through the lens of AEDP (Accelerated Experiential

\section{DATA AVAILABILITY STATEMENT}

The raw data supporting the conclusions of this article will be made available by the authors, without undue reservation.

\section{AUTHOR CONTRIBUTIONS}

All authors listed have made a substantial, direct and intellectual contribution to the work, and approved it for publication.

Dynamic Psychotherapy). Couns. Psychol. Q. doi: 10.1080/09515070.2020. 1771283. [Epub ahead of print].

Meichenbaum, D. (2012). Roadmap to Resilience: A Guide for Military, Trauma Victims and Their Families. Bethel, CT: Crown House Publishing Ltd.

Miller, A. (2008). A critique of positive psychology-or 'The new science of happiness'. J. Philos. Educ. 42, 591-608. doi: 10.1111/j.1467-9752.2008. 00646.x

Mitchell, S. (1988). Tao Te Ching. New York, NY: Harper Perennial Publishers.

Seligman, M. E. P. (1998). American psychological association president's address. Am. Psychol. 54, 559-562.

Seligman, M. E. P., and Csikszentmihalyi, M. (2000). Positive psychology: An introduction. Am. Psychol. 55, 5-14. doi: 10.1037/0003-066X.55.1.5

Seligman, M. E. P., Tracy, A. S., Park, N., and Peterson, C. (2005). Positive psychology progress: empirical validation of interventions. Am. Psychol. 60, 410-421. doi: 10.1037/0003-066X.60.5.410

Van Tongeren, D. R., and Showalter Van Tongeren, S. A. (2020). The Courage to Suffer: A New Clinical Framework for Life's Greatest Crises. 1st Edn, West Conshohocken: Templeton Press.

Wong, P. T. (2011). Positive psychology 2.0: towards a balanced interactive model of good life. Can. Psychol. 52, 69-81. doi: 10.1037/a0022511

Wong, P. T. (2019). Second wave positive psychology's (PP 2.0) contribution to counselling psychology. Couns. Psychol. Q. 32, 275-284. doi: 10.1080/09515070. 2019.1671320

Wong, P. T. (2021). What is Existential Positive Psychology (PP 2.0)? Why is it Necessary for Mental Health During the Pandemic?. Available online at: http://www.drpaulwong.com/what-is-existential-positive-psychology-whyis-it-necessary-for-mental-health-during-the-pandemic/ (accessed January 5, 2021)

Wong, P. T. P., and Bowers, V. (2018). "Mature happiness and global wellbeing in difficult times," in Scientific Concepts Behind Happiness, Kindness, and Empathy in Contemporary Society, ed. N. R. Silton (IGI Global), 112-134.

Yakushko, O., and Blodgett, E. (2018). Negative reflections about positive psychology: on constraining the field to a focus on happiness and personal achievement. J. Humanist. Psychol. 61, 104-131. doi: 10.1177/ 0022167818794551

Zweig, C., and Abrams, J. (eds). (1991). Meeting the Shadow: The Hidden Power of the Dark Side of Human Nature. New York, NY: Jeremy p. Tarcher/Penguine.

Zweig, C., and Wolf, S. (1997). Romancing the Shadow: A Guide to Soul Work for a Vital, Authentic Life. New York, NY: Ballantine Book.

Conflict of Interest: The authors declare that the research was conducted in the absence of any commercial or financial relationships that could be construed as a potential conflict of interest.

Copyright (c) 2021 Bai, Berry, Haber and Cohen. This is an open-access article distributed under the terms of the Creative Commons Attribution License (CC BY). The use, distribution or reproduction in other forums is permitted, provided the original author(s) and the copyright owner(s) are credited and that the original publication in this journal is cited, in accordance with accepted academic practice. No use, distribution or reproduction is permitted which does not comply with these terms. 